\title{
Optics curriculum development at the Optical Sciences Center
}

\section{Richard Shoemaker}

Richard L. Shoemaker, "Optics curriculum development at the Optical Sciences Center," Proc. SPIE 4588, Seventh International Conference on Education and Training in Optics and Photonics, (28 May 2002); doi: 10.1117/12.468706

SPIE Event: Education and Training in Optics and Photonics 2001, 2001, Singapore, Singapore 
Invited Paper

\title{
Optics Curriculum Development at the Optical Sciences Center
}

\author{
Richard L. Shoemaker ${ }^{*}$, Optical Sciences Center, University of Arizona
}

\begin{abstract}
The broad scope and interdisciplinary nature of optics makes it difficult to develop an optics curriculum with sufficient breadth and depth to adequately teach the material one would like a graduating student to know, and to effectively prepare them for a career in optics. The University of Arizona's Optical Sciences Center offers M.S. and Ph.D. graduate programs as well as an undergraduate B.S. program, with each of these programs having distinctly different goals and curricula. The primary intent of the Ph.D. program is to provide the student with a broad basic optics education plus indepth education and research experience in a sub-field of optics, while the primary intent of the M.S. program is to provide students with either an in-depth education in a particular optics sub-field or a broad basic optics education. The undergraduate program prepares students for an industrial optics career at the junior engineer level, with tracks or minors that allow a student to also acquire competence in any one of several related fields. In this paper, the various curricula and related examinations that have been developed for these three programs are discussed, along with the considerations that drove their development, their successes, and their shortcomings.
\end{abstract}

Keywords: optics curriculum development, graduate, undergraduate, optics education, optical engineering education

\section{INTRODUCTION}

Since the founding of the Optical Sciences Center, the faculty and the Center's directors have envisioned the Center as a place that offers students the opportunity to obtain a broad-based education in the optical sciences that covers nearly the entire breadth of the subject. Two key factors allowed the Center to implement this vision over the years. The first is that the Center is a separate, single department with its own classrooms, laboratories, courses, budget, permanent faculty, and students, and is not a paper entity whose faculty have their primary appointments in Electrical Engineering or Physics. The second factor is that in hiring new faculty, the Center's directors have tried to maintain a balance between the number of faculty whose interests lie at the optical physics end of the spectrum, those whose interests are in some area of applied optics or optical devices, and those whose interests lie at the classical optical engineering end of the spectrum. This provides the Center with a faculty having a very broad range of expertise that can provide research opportunities for the students in all areas of optics, and allows the Center to offer a very broad spectrum of courses in optical sciences.

In the following sections, I trace the development of the curricula and related examinations for the degree programs that the Center offers, along with the considerations that drove their development, their successes, and their shortcomings. Since the various degree programs each have their own distinct goals and curricula, each degree program will be considered separately.

\section{EARLY HISTORY}

In 1964, under the leadership of Aden B. Meinel, an Optical Sciences program was established at the University of Arizona, with initial support coming from the university and ARPA. In the fall of 1965, the academic program in Optical Sciences began operation with five faculty, an enrollment of four graduate students, and a curriculum of seven courses: ${ }^{1}$

$\begin{array}{lll}\text { OPTI } & 206 & \text { Introduction to the Optical Sciences } \\ \text { OPTI } & 207 & \text { Optical Design } \\ \text { OPTI } & 220 & \text { Spectroscopy }\end{array}$
* Shoemaker@ optics.arizona.edu; phone 520 621-2825; http://www.optics.arizona.edu; Optical Sciences Center,
University of Arizona, Tucson, AZ, USA 85721-0094 


$\begin{array}{lll}\text { OPTI } & 226 & \text { Optical Instrumentation } \\ \text { OPTI } & 337 \mathrm{a} & \text { Interference, Diffraction, and Image Formation I } \\ \text { OPTI } & 337 \mathrm{~b} & \text { Interference, Diffraction, and Image Formation II } \\ \text { OPTI } & 347 & \text { Laser Physics }\end{array}$

The outlines of much of the later core curriculum can already be seen here, in that the courses include balanced coverage of most of what was then regarded as optics, with two courses in the area of geometrical optics (OPTI 207 and OPTI 226), two courses in optical physics (OPTI 220 and OPTI 347), and two courses in physical optics (OPTI 337a and OPTI 337b).

Thanks to a large multi-year grant from the US Air Force and continued university support, the program was able to grow dramatically from this small beginning into a major, independent graduate research and education unit, the Optical Sciences Center, during the next few years. The university gave the Center authority to grant its own M.S. and Ph.D. degrees in June 1967, and the Center's original building was completed in late 1969. By 1970, the Center had 16 permanent faculty plus four additional faculty with joint appointments in Optical Sciences, 63 graduate students, twothirds of whom were Ph.D. students, and a curriculum consisting of 46 graduate courses in Optical Sciences plus seven courses that were cross-listed from other departments. ${ }^{2}$

Despite the tremendous growth in the number of courses, there was still no required or recommended curriculum at this point, and students were free to pick and choose from the courses as they wished. However, the students at the time found it difficult to pick an appropriate set of courses that would offer them the basic material they needed to know in order to pass the comprehensive examination and also provide a broad basic education in optics. They requested that a standard series of introductory courses (i.e., a core curriculum) for all Ph.D. students be developed, and in 1971 this was finally accomplished.

Also in 1971, a new degree, called an Optical Specialist degree, was introduced. ${ }^{2}$ This was an intensive 12-month degree program intended for students who had already obtained an M.S. degree in optics, physics, mathematics, or engineering, and were currently employed in the field of optical science or technology. It differed from a Ph.D. program in that it was intended to be more specialized, no dissertation or thesis research was required, and the program was meant to be completed in one year of full-time study. However, there turned out to be little student interest in this degree, and this degree program was terminated within a few years of its initiation with only 3 graduates having obtained an Optical Specialist degree.

In the remaining sections, the curriculum development of the M.S., and Ph.D. degree programs are examined, followed by a discussion of the more recently developed undergraduate B.S. curriculum.

\section{M.S. CURRICULUM DEVELOPMENT}

The curriculum for M.S. students is quite distinct from the Center's other curricula. We have many students who come to the Center to obtain an M.S. degree and have little interest in a PhD. Many of these are mature students who are returning to school from industry or government laboratories. They also often have a goal of obtaining in-depth knowledge of a particular area of optics. As a result, the M.S. curriculum has never had any required courses. Instead students work with an academic advisor to create a curriculum from the Center's 71 graduate courses that is specifically tailored to their needs and interests. The students take 24 units of graduate coursework (our courses are typically 3-unit courses, so this is about 8 courses), and then complete a Master's thesis, for which they receive eight units of credit. In 1983, in order to ensure that no M.S. students would graduate without having hands-on experience in an optics laboratory, a requirement was added that students take at least two optics laboratory courses as part of their program of study.

Because the Center offers so many graduate courses (46 courses in 1970, growing to 71 courses at present), students can pick from numerous different areas of optics in which to specialize, although some of these areas will change over time as faculty and research areas change. For example, in 1970, there were four courses offered in photography and film recording, and three courses offered in glass technology. Currently we offer no courses in these areas. On the other hand, we now have many courses in areas that didn't even exist in 1970, such as seven courses in integrated and fiber optics. 
Many of the students coming from government, military, or industrial labs face an significant constraint on their academic program because they are required by their sponsors to complete their degree work in a fixed (and often short) time period, with little flexibility. This creates a problem, since it's very difficult for students to determine in advance how it will take them to complete their M.S. thesis research and finish writing the thesis. To better serve these students, the Center created a non-thesis M.S. degree option in 1983. Under this option, students take more courses, completing 32 units (about 11 courses) of graduate coursework, and then writing a final Master's Report instead of an M.S. thesis. The Master's Report is more on the scale of a large term paper and normally requires only library research of an assigned topic, not open-ended laboratory research.

There is also a final oral Master's examination, taken after all other requirements have been completed. In the case of students who choose to write an M.S. thesis, the oral exam questioning is based largely on the thesis work, while the questioning for students choosing the non-thesis option is based largely on the coursework they have taken.

Although a good proportion of our M.S. students are people returning to school from an industrial or government position, many others are simply unable to leave their jobs for the 1-1/2 to 2 years that it takes to earn a Masters degree. To offer these students a better opportunity to obtain an M.S., as well as to serve students who just want to take some graduate optics courses without leaving their jobs, the Center decided in 1986 to start offering two courses per semester on video. These courses are available by satellite broadcast via NTU (National Technological University), or by video tape through the University of Arizona's Extended University. Originally, the video courses rotated through a sequence of six different graduate courses, but the number of different courses offered has slowly expanded over the years to a total of 10 different courses, consisting of our eight core courses (see below) plus a course on optical detectors and an introduction to lasers course. As a result, M.S. students can take most of their course work by video or satellite broadcast, but they must come to the UA campus and be enrolled as a full-time student for at least one semester. The Center has resisted the request of some students to offer an M.S. degree that can be completed without ever coming to the university because we feel that the experience of interacting personally with faculty and other students and the completion of one or two hands-on optics laboratory courses is just too valuable to drop.

\section{Ph.D. CURRICULUM DEVELOPMENT}

From its inception, the Ph.D. program has required students to take approximately 54 units of coursework (about 18 courses), complete a satisfactory Ph.D. dissertation, and pass two major exams. The first exam is the comprehensive examination (this was called the preliminary examination up until a few years ago) that is typically taken after two to three years of graduate study has been completed. This exam is closely tied to the core curriculum offered by the Center and is discussed in detail below. The second exam is the final examination. This is the traditional oral dissertation defense that is done after the student has completed their Ph.D. dissertation and all their coursework.

While the majority of our students take all of their graduate coursework in Optical Sciences, the Center has always had a very liberal policy in allowing courses from other departments to be counted as part of a student's Ph.D. coursework, as long as those courses are relevant to their degree program in some substantial way. Thus a number of students include courses in physics, mathematics, astronomy, or one of the engineering departments in their studies. This policy fits well with the interdisciplinary nature of much optics research. Although the University of Arizona requires all Ph.D. students to have both a major and a minor, it also allows students to both major and minor in the same department. Due to our liberal policy in allowing students to include courses from other departments in their studies, it is very rare for an Optical Sciences student to actually minor in another department, since declaring a formal minor in another subject typically requires the student to take an additional written minor examination, and also to include two faculty members from the minor department on the oral portion of their comprehensive examination.

The single coursework requirement for all Ph.D. students is that they take at least two optics laboratory courses. This policy was adopted early in the Center's history, and is meant to ensure that no student will graduate without having had hands-on experience in an optics laboratory. However, we do allow one laboratory course to be waived for those students who have previously had significant optics laboratory experience.

Another University of Arizona requirement for Ph.D. students is that they take a qualifying examination during their first semester of graduate work. The university's purpose in requiring this examination is to determine if the student has had sufficient undergraduate preparation in their major area to begin their graduate studies. However, this presents a problem in optical sciences because very few beginning graduate students have a degree in optics. Typically, over half 
of the Center's entering Ph.D. students have a degree in physics, about one-third have a degree in electrical engineering, and the remainder have degrees in a variety of other engineering disciplines or in applied mathematics. With this mix of backgrounds, it makes it nearly impossible to give an optics qualifying examination. When the Center's Ph.D. program began operation, a qualifying examination was given as an oral exam, but this never proved to be satisfactory. For example, it was very difficult for faculty members whose background was in optics to fairly evaluate the preparation of an electrical engineering major. In practice, the exam tended to just be an examination of the student's mathematical skills, or worse, just a kind of general intelligence test. Sometime during the 1970s, the Center convinced the university to allow the qualifying examination to be replaced with a "qualifying interview". The interview is done with a faculty member picked by the student, and takes place in the latter part of the student's first semester at the Center. The purpose of this interview is to discuss how the student is doing in their coursework, and to determine if any major problems are evident.

The qualifying interview idea was later expanded to cover all graduate students, and is known as the annual "progress interview". Each year, every student is required to pick a faculty member who is not their research advisor, and sit down to discuss with them their progress to date as well as any problems in their research or coursework that may be bothering them. For both the qualifying and progress interviews, the faculty member provides written report of the interview that is given to both the student's research advisor and to the academic office.

\subsection{The Ph.D. Core Curriculum}

This has probably been the area of the greatest changes and discussion over the years. As mentioned in Sec. 2 above, a set of core courses was created in 1971, largely at the request of the Ph.D. students. While these core courses are not required, their content represent represents the knowledge that the faculty believe all graduating Ph.D. students should have mastered, and the questioning on the written and oral Prelim Exams (now known as the Comprehensive Exam) is based in whole or in part on the core course material. Any changes to the core courses, or to the core course syllabi, require approval by a vote of the Center faculty.

The original core courses consisted of a set of five courses:

OPTI 201 - Fundamentals of Optics (essentially an electromagnetic waves course)

OPTI 202 - Linear Theory in Optics

OPTI 204 - Geometrical Optics

OPTI 206 - Interference and Diffraction

OPTI 209 - Interaction of Radiation with Matter

In 1975 a sixth core course was added,

OPTI 210 - Introduction to Optical Engineering (radiometry and detectors),

and in 1977 a seventh core course was added,

OPTI 207 - Optical Design.

In 1980, after the University changed its course numbering system so that all 200 level courses became 500 level courses, two additional core courses,

OPTI 507 - Introduction to Solid-state Optics

and OPTI 508 - Probability and Statistics in Optics,

were added. Some renaming and revision of the previously existing core courses was done as well at that time.

The four core courses added to the original set were established as gaps were found in the knowledge of students going through the program (prompting the addition of the Optical Design and the Probability and Statistics in Optics courses), and as new areas of optics became increasingly important (hence the Radiometry and Detectors and the Introduction to Solid-state Optics course additions). The core courses were also grouped into five categories: Physical optics (OPTI 201 and OPTI 206), geometrical optics (OPTI 204 and OPTI 207), radiometry and detectors (OPTI 210), quantum optics (OPTI 209 and OPTI 507), and mathematical optics (OPTI 202 and OPTI 508).

This set of core courses remained stable for about ten years. However, in the late 1980's, pressure from some faculty members had grown to add more new topics to the existing core courses and/or to add additional core courses. At the same time, other faculty members felt that nine core courses was already too many because students needed more time to 
take the variety of specialized optics courses that had been added to the curriculum and were essential for students doing research in particular areas. These opposing viewpoints occur because the Center's core courses actually serve two purposes: They are intended to provide the broad education that will serve the students by giving them a base of knowledge that will last them throughout their careers, but they are also intended to provide them with the basic knowledge they need to get started in their research. The latter purpose is an important consideration, because the great majority of our incoming $\mathrm{PhD}$ students are offered a graduate research assistantship when they are admitted, and are expected to join a group within four to six weeks after they arrive in the fall. This creates substantial pressure from the faculty to get the students through the core courses and the comprehensive exam (which is based on the core courses) and move on to more specialized courses as soon as possible.

In 1990, the curriculum committee proposed a major revision to the core courses to address these tensions. They recommended that the core courses be grouped into four categories: Electromagnetic theory and physical optics, geometric optics and optical engineering, quantum optics and solid-state optics, and Image science and mathematical methods. In each category, there would be three courses. Two courses in each category would come from the existing core courses, which would be slightly condensed from nine to eight courses by splitting up the material in the Radiometry and Detectors course, and distributing it among several of the other existing core courses. In addition there would be one new 4-unit survey core course in each category that covered much of the same material offered by the other two core courses in that category, but the coverage would be at more of a survey level than the in-depth coverage offered by the other two core courses. The intent was that students could choose to take the single survey core course in two of the four categories, and the two-course core sequence in the other two categories, so that a total of only six courses would be needed to cover the core. This proposal was adopted in 1991.

A further recommendation by the 1990 curriculum committee was that we rationalize and add to the optics laboratory courses that existed at that time by creating a set of four core laboratory courses, one for each of the four categories. These core laboratory courses were

OPTI 505L Fundamentals of Physical Optics Lab

OPTI 510L Fundamentals of Applied Optics Lab

OPTI 511L Lasers and Solid-State Devices Lab

OPTI 512L Mathematical Optics Lab

The faculty also adopted this recommendation in 1991. Most M.S. and Ph.D students take only two of these four laboratory courses, or one of these labs plus a more specialized laboratory course such as OPTI 513L, Optical Testing Lab, or OPTI 587, Fiber Optics Laboratory. This set of four core laboratory courses has worked well, and it remains in place at the present time.

However, by 1993, it was apparent that the new core course curriculum had some significant problems. First, the students disliked the 4-unit survey-level courses, saying that they covered too much material too rapidly to learn well, and enrollment in two of them dropped off dramatically. Second, many of the faculty and students felt that the subjects of radiometry and detectors, which had been distributed among several other core courses in the 1990 revision, were now receiving inadequate coverage. A final problem related to the comprehensive examination. The core courses are supposed to provide students with an adequate background to take and pass this examination, but the survey-level courses were not doing that job well enough, and many students decided that the only way to properly prepare for the comprehensive exam was to take all of the two-course in-depth core sequences, and in some cases one or two of the survey-level core courses as well, thus defeating the purpose of the 1990 core revision.

As a result, a new curriculum committee recommended was that all the 4-unit survey-level core courses be eliminated, and that material covering radiometry and detectors be reintroduced into the geometrical optics core category. In order to make room for this material, much of the core material on aberrations was moved out of the core into a new course, Introduction to Aberrations. While this was not a core course, it was expected that almost all Ph.D. students other than those specializing in quantum optics would take this course. The faculty approved this recommendation in 1993, and the eight core courses were then

OPTI 501 Electromagnetic Waves

OPTI 505 Diffraction and Interferometry 
OPTI 502 Introduction to Optical Design

OPTI 506 Radiometry and Detectors

OPTI 511 Introduction to Optical Physics and Lasers

OPTI 507 Solid-State Optics

OPTI 512 Introduction to Fourier Optics

OPTI 508 Probability and Statistics in Optics

These eight core courses still remain as our core curriculum as of this writing. Detailed syllabi for these core courses as well as all of the other optics courses offered by the Optical Sciences Center can be found on our web site, www.optics.arizona.edu.

Since a number of Ph.D. student arrive at the Center already possessing a strong background in subjects such as electromagnetism and/or quantum mechanics, advanced alternatives to the core courses in optical physics and lasers and in electromagnetic waves were also established at this time. Although they have not been used as core course alternatives as much as had originally been hoped, the courses have been reasonably popular and remain in the curriculum.

In the last few years, the tremendous expansion of optical communications and the explosion of new photonics devices that went along with it have created an obvious need to put more emphasis on photonics in the core curriculum.

Although some of this material is covered in the present core, and the Center has a number of advanced graduate courses in the area, nearly all faculty and students recognize that more thorough coverage is now needed in the core curriculum. The syllabus for a new core photonics course has been created and will likely be established starting in the fall of 2002. The problem, however, is that simply doing this will again increase the number of core courses, and this is favored by very few people. As a result, the faculty is currently considering curriculum committee proposals to create a dual-track core curriculum. Students would choose to take either a quantum optics track with core courses that offer more coverage of optical physics, or and applied optics track with core courses that offer more coverage of optical engineering topics. At this writing, it remains to be seen if the faculty will adopt these proposals.

\subsection{The Ph.D. Comprehensive Examination}

The University of Arizona requires that all Ph.D. students pass a Comprehensive Examination (formerly known as a Preliminary Examination). This examination consists of two parts - a written exam and an oral exam. Students must pass the written exam before they can take the oral examination. Students typically take this exam after they have been at the Center for 2 or 2-1/2 years and have completed 32 units of coursework, including all or nearly all of the core courses.

Each year, the written comprehensive exam is offered in September and again in February, and is administered during the mornings of two consecutive days. Until 1993, the first morning session contained questions drawn from the core courses, while the second morning session contained questions drawn from more advanced courses. Students could elect to answer one of two questions in each of the five core course categories (Physical optics; Geometrical optics;

Radiometry and detectors; and Mathematical optics) on the first morning, and select any five out of fifteen questions on the second morning. Questions for the written comprehensive exam are solicited from the faculty for each exam, and are then reviewed, and sometimes modified or reworded, by a Written Comprehensive Exam Committee. The questions from all previous written comprehensive exams are made available to the graduate students, who use them extensively as study and exam preparation guides.

With the 1991 core course revision, the subject categories were reduced from five areas to four areas: Electromagnetic theory and physical optics; Geometric optics and optical engineering; Quantum optics and solid-state optics; and Image science and mathematical methods. As a result the written prelim structure was also changed so that students could elect to answer two of three questions in each of the four core course areas on the first day, and select any five out of sixteen questions on the second day.

Each faculty member who contributed a given question to the written comprehensive exam grades the answers to that question, and the Written Comprehensive Exam Committee then meets to determine which students pass the exam. Each exam question is graded on a 10-point scale according to a set of written criteria given to each grader in order to ensure some uniformity of grading. The minimum passing score is not a set number and hence its determination by the committee is inevitably somewhat subjective. To make sure that personal considerations do not enter into the grading or 
the pass/fail determination, each student taking the exam is given a code number and no names appear on the exam papers. Only after the pass/fail determinations have been made does the Written Comprehensive Exam Committee learn the names of the students. Typically about $80 \%$ of the Center's Ph.D. students pass the written comprehensive exam on the first attempt, and they are automatically allowed to repeat the exam a second time if they fail on the first attempt. A third or even a fourth attempt at the exam can also be made by students who fail on previous tries, if they petition the committee and obtain their approval.

Nearly all of the Center's faculty and students (or at least those who have already completed the comprehensive exam!) agree that this exam is one of the most valuable features of the Ph.D. academic program. Students typically put in several months studying for this exam, and are encouraged to form small study groups of three or four people during the period they are preparing for the exam. By having to review the entire range of optics material they've learned in their courses for one exam, the students find that they not only gain a much better understanding of the material, but also make many connections between the material covered in one course and related material covered in other courses.

However, by 1998, difficulties in selecting an appropriate set of second day written comprehensive exam questions from the large number of graduate courses being offered were becoming increasingly clear, students were postponing taking the exam beyond the desired two-year point, and some students were selecting advanced courses on the basis of how often questions from a particular course appeared on the written exam. As a result, the curriculum committee proposed, and the faculty adopted, a new written comprehensive exam format. Beginning in the fall of 1999, the written comprehensive exam questions are based only on the core courses. The material in the core courses was divided into 17 general topic areas, and 12 written prelim exam questions are prepared for each semester's exam, one question coming from each of 12 topic areas selected at random from the 17 areas. Students are required to answer all 12 questions, but the two lowest scores obtained on the questions are thrown out for the purposes of determining whether the student passes or fails. To date, this formulation of the exam appears to be working reasonably well.

The oral comprehensive exam can only be taken after the student has passed the written portion of the exam. Like the written portion, this exam is intended primarily to test the student's broad knowledge of optics. In order to ensure that this is done, the oral comprehensive exam committee for each student is chosen by the Center's Associate Director for Academic Programs. Until the mid-1980's, the oral exam committee consisted of five faculty members. One faculty member is the student's dissertation advisor, and the other four faculty members were each specialized in a different one of the five core curriculum categories. In the mid-1980's, the Center obtained permission from the university to use four-person oral comprehensive exam committees, so only four of the five core course categories were then represented on the exam, but with the reduction to four categories in 1991, there was again representation of all categories on the examination committee.

Since the new written comprehensive exam doesn't probe the student's knowledge and preparation in his or her area of specialization, a new oral exam, the Dissertation Proposal Exam, was instituted at the same time. Taken about a year after the prelim exam, this is an oral exam whose examiners are the student's three-member dissertation exam committee. The student prepares a brief dissertation proposal, and the committee evaluates both the scope and quality of the proposal and the student's preparation in his or her area of specialization. This committee remains in place throughout the student's dissertation research and also serves as the committee for the student's final oral dissertation defense.

\section{B.S. CURRICULUM DEVELOPMENT}

In the 1980s, the Optical Sciences Center was hearing an increasing number of pleas from the optics industry for an optics degree program that would produce graduates at the baccalaureate level. The Center responded by creating an undergraduate degree program in optical engineering, which began operation in 1989. The first B.S. degree was awarded in $1992 .^{3}$

Getting this degree program approved, and finding an appropriate administrative structure, turned out to be more involved than was originally envisaged, because the Center was (and still is) a freestanding academic and research unit that is not a traditional department in any university college. Furthermore, it had not previously offered any previous undergraduate courses or degrees. As a result, the provost at the time told the Center that it could not offer an undergraduate degree program on its own, but would need to offer it as a joint program under the administrative control of another department. The Electrical and Computer Engineering (ECE) department was selected as the academic 
partner. The ECE academic office handled the administration of the program, while the contents of the curriculum and other curricular matters were handled by a joint curriculum committee consisting of four faculty members from ECE and four faculty members from Optical Sciences. Thanks to the good will on the part of the faculty in both departments, and their desire to see the program thrive, this cooperative arrangement actually worked very well.

The Bachelor of Science in Optical Engineering degree program that was created has a distinctly different emphasis from the graduate program. The intent was that this be primarily a terminal degree program whose graduates would be prepared to immediately work in industry as optical engineers, rather than a degree program that prepared students for graduate work. The lecture courses roughly parallel our graduate core courses, but there is more of an engineering emphasis, and there is a much stronger laboratory component to this curriculum than is present in the graduate curriculum.

The courses in the original curriculum remained nearly unchanged throughout the 1990s, except for the replacement of an engineering mathematics course by a Fourier optics course and the separation of the laboratory and lecture components of the Geometrical Optics and Physical Optics courses. The required optics courses in the optical engineering curriculum were:

$\begin{array}{ll}\text { OPTI 210 } & \text { Geometrical Optics } \\ \text { OPTI 210L } & \text { Geometrical Optics Laboratory } \\ \text { OPTI 226 } & \text { Physical Optics } \\ \text { OPTI 226L } & \text { Physical Optics Laboratory } \\ \text { OPTI 342 } & \text { Fourier Optics } \\ \text { OPTI 350 } & \text { Radiometry, Sources, and Detectors } \\ \text { OPTI 370 } & \text { Lasers and Electro-Optical Devices } \\ \text { OPTI 412 } & \text { Optical Instrumentation } \\ \text { OPTI 416 } & \text { Optical Design, Fabrication, and Testing } \\ \text { OPTI 470a } & \text { Optics Laboratory } \\ \text { OPTI 470b } & \text { Optics Laboratory }\end{array}$

In addition, because this was a joint program with ECE, students were required to take seven electrical engineering courses, four semesters of calculus, three semesters of chemistry, and three semesters of physics. The optics curriculum itself actually started in the sophomore year, as all freshman engineering students take a common set of courses in English, humanities, calculus, chemistry, and physics. The 200-level courses are intended to be taken in the student's sophomore year, the 300-level courses in the student's junior year, and the 400-level courses in the student's senior year.

In the last three or four years, we began to hear increasing calls from the optical industry, and from the students themselves, to broaden the curriculum so that students would be able to supplement the optics courses with a concentration in engineering areas other than electrical engineering, such as mechanical engineering or materials science. However, there was no reasonable way to do this when the program was administered in electrical engineering, and in practice was treated by ECE as being simply one of three tracks in the ECE curriculum (the other two being computer engineering and electrical engineering). Having all the optics courses and labs in one department, but all the program administration in another department on the other side of campus was also awkward, and created some difficulties in communication and coordination in the areas of student advising and student recruiting. Finally, in 1999, after discussions between the Center's director, Richard Powell, and then provost, Paul Sypherd, the decision was made to allow a transfer of the undergraduate program to Optical Sciences, along with a change in the name of the degree to Bachelor of Science in Optics (because no degree program outside the College of Engineering was allowed to use the word "engineering" in its name).

As the program transfer worked its way through the university system, the Faculty Senate decided that no undergraduate program could be offered unless that degree program (though not necessarily the department offering the program) was given under the auspices of one of the colleges within the university. The college that was picked for the B.S. in Optics program was University College, which at the University of Arizona, is the college that handles students in the general studies program (i.e., those who have not selected a specific major), as well as a few other specialized degree programs. With the condition that the college-level administration of the program be with University College, the program transfer was approved, and the first class of students began their studies in the fall of 2000. 
During the 15-month time period that the program transfer was in progress, an Undergraduate Curriculum Committee was formed in Optical Sciences, and they decided to evaluate the entire program thoroughly to see how shortcomings that had been perceived in the existing program might be eliminated. The committee had several goals in mind as they did the curriculum revision:

1. To expand the options available for the students so that in addition to learning optical engineering, they could take a concentration of several courses in another subject area.

2. To provide a better ordering of the course material in the curriculum, that would keep student interest high right from the start and increase the coupling between related classes.

3. To increase the amount of hands-on optics laboratory experiences offered to the students.

4. To increase the breadth of optics material that the students were taught, and especially to provide more coursework in the new areas of optical communication and photonics.

The set of required optics courses that the committee developed for the new curriculum is as follows:

OPTI 201R Geometrical and Instrumental Optics I

OPTI 201L Geometrical and Instrumental Optics Laboratory I

OPTI 202R Geometrical and Instrumental Optics II

OPTI 202L Geometrical and Instrumental Optics Laboratory II

OPTI 280 Computer Programming Workshop

OPTI $310 \quad$ Physical Optics I

OPTI $330 \quad$ Physical Optics II

OPTI $340 \quad$ Optical Design

OPTI 360 Electronics for Optical Engineers and Scientists

OPTI 370 Lasers and Photonic Devices

OPTI 380A Intermediate Optics Laboratory I

OPTI 380B Intermediate Optics Laboratory II

OPTI 400 Radiometry, Sources, and Detectors

OPTI 410 Optical Fabrication and Testing

OPTI 420 Opto-mechanical Design

OPTI $430 \quad$ Optical Communications

OPTI 470A Optics Laboratory I

OPTI 470B Optics Laboratory II

OPTI 498 Senior Capstone

In total, the number of optics courses in this curriculum was expanded from the previous 11 courses to 19 courses, although two of the new courses, OPTI 280 and OPTI 360, are really alternatives to ECE courses in the previous curriculum. The calculus, chemistry, and physics requirements of the previous curriculum remained unchanged, but the seven required electrical engineering courses were replaced by the requirement that students select a minor subject in which they would typically take six courses. Students could select from a wide choice of minors, including mathematics, physics, chemistry, astronomy, any engineering area, and even business. Other highlights of this curriculum change include the addition of two new optics laboratory courses in the junior year (OPTI 380A and 380B), new optical communications and opto-mechanics courses in the senior year (OPTI 430 and OPTI 420), and expansion of the Optical Design, Fabrication, and Testing course (OPTI 416) into two courses (OPTI 340 and OPTI 410). A final senior design project course, OPTI 498, was also added.

Last, but not least, the previous sophomore Geometrical Optics course (OPTI 210), which is the first optics course that students take, was combined with the Optical Instrumentation course (OPTI 412) to create a two-semester sophomore course sequence, Geometrical and Instrumental Optics I and II. The idea here is to combine, in the same course, the basic geometric optics theoretical material with its applications to the design of actual optical instruments. It is hoped that this change will both keep the material more interesting, and enhance the student's grasp of the theoretical principles by seeing them applied to real instruments. A further advantage of putting two semesters of geometrical optics into the sophomore year is that it allows the previous Physical Optics course (OPTI 226) to be moved to the junior year. By that time, the students will have completed their entire four-semester calculus and three-semester physics sequences, and therefore should be better prepared for this more mathematically intensive subject. At the same time, the previous 
Fourier Optics course was integrated with Physical Optics into a two-semester sequence (OPTI 310 and OPTI 330). Further details about the contents and philosophy of this new curriculum can be found in Ref. 4.

Although the new B.S. in Optics curriculum has just begun to take effect, there is yet one more change currently underway. Because the University of Arizona is known worldwide for is its optically related programs (in Optical Sciences, Astronomy, and Planetary Sciences) and its astronomical observatories, the administration of the College of Engineering and Mines was quite unhappy to find itself with no programs in optics after the program transfer occurred. As a result, the college dean was able to convince the new provost that college-level administration of the B.S. in Optics program should reside in the Engineering College rather than University College. Given its engineering emphasis, this is actually a more sensible home for the undergraduate optics program. Thus a second program transfer is now in progress which will result in the B.S. program (but not the Optical Sciences Center itself, or any of its other academic programs) being housed in the College of Engineering and Mines for the purposes of college level functions (grade appeals, recruiting, etc.). Department-level administration and control of the curriculum, however, will remain in Optical Sciences. Functionally, the result is that the Optical Sciences Center appears in the engineering college with the status of an undergraduate department.

This second program transfer should produce several advantages. First, the program name will change upon the transfer to Bachelor of Science in Optical Science and Engineering, which is more properly descriptive of its contents. Also, inclusion of the program in the engineering college should help in student recruiting, since they will provide us with recruiting assistance from the student base that we are interested in, and the program will be more visible and much easier to find by appearing in Engineering College printed and on-line materials rather than in University College materials. The curriculum will remain almost unchanged, except that one general education course will be replaced by a freshman course, Introduction to Engineering (ENGR 102), the 18-unit concentrations in other subjects will be called tracks rather than minors, and the Senior Capstone course (OPTI 498) will be replaced by a two-semester interdisciplinary senior capstone course sequence (ENGR 498A and 498B).

Finally, it appears that this transfer will result in ABET accreditation of the undergraduate optical engineering program. With the help of the Engineering College, ABET accreditation has already been applied for. The required self-study documentation was submitted in June 2001, and an ABET site visit was conducted in October 2001. The site visitors have told us that our program appears to meet ABET criteria, and that they strongly support it. We anticipate that the ABET commission will vote to formally accredit the program at their next meeting in July of 2002. As this program is only the second program in optical engineering in the USA to be accredited (a small program at the University of Alabama - Huntsville was accredited several years ago), we hope that it will serve as a model for future programs in optical engineering at other colleges and universities.

\section{ACKNOWLEDGMENTS}

I would like to thank the Optical Sciences Center faculty, especially those members who have served on the Center's curriculum committees, for their teaching and curriculum design efforts over the years. Their contributions have made the Center the outstanding academic unit that it is today.

\section{REFERENCES}

1. A. B. Meinel, A Plan for an Optical Sciences Center, Technical Report 0, Optical Sciences Center, Tucson, AZ, 1965.

2. J. A. Eyer, Optical Sciences Center Newsletter, Vol. 4, No. 1, January 1970.

3. J. D. Gaskill, J. E. Palmer, and M. J. Nofziger, "Undergraduate Optical Engineering at the University of Arizona", Proc. SPIE / 1995 International Conference on Education in Optics, Vol. 2525, pp. 123-125, Oct.1995.

4. J. M. Palmer, "An Undergraduate Optics Program for the $21^{\text {st }}$ Century", Proc. SPIE / Seventh International Conference on Education and Training in Optics and Photonics, Vol. 4588 (in press). 